\title{
A CONCEPÇÃO DE SUBJETIVIDADE EM LÉVINAS: DA SOLIDÃO DA HIPÓSTASE AO ENCONTRO COM A ALTERIDADE
}

\author{
Jacqueline de Oliveira Moreira* \\ Pe. Ulpiano Vazquez Moro, $S^{* *}$
}

\begin{abstract}
RESUMO
Este artigo pretende ser uma introdução ao pensamento de Lévinas a partir da discussão sobre a problemática da subjetividade. Tentaremos acompanhar os movimentos da filosofia levinasiana, iniciando com a crítica ao Eu concebido pelo pensamento moderno, até a proposta desse autor que revela a alteridade como condição de possibilidade da subjetividade. Lévinas revela que o existente, para existir, tem que se afirmar virilmente, marcando assim uma posição solitária. Será o encontro com a morte que colocará algo que não pode ser assimilado. Amorte aparece como alteridade. Lévinas não pensa a morte como um nada, mas como um mistério que apresenta um limite para o meu eu solitário e coloca a possibilidade de existir algo além de mim. Em seguida, o autor aproxima o amor e a morte; a experiência de amor é como a morte, algo que me invade, algo sobre o qual não tenho controle, mas sobrevivo nele. E a partir de Eros o sujeito se lança na aventura da paternidade e da fecundidade. Essas experiências revelam o rosto do outro no filho que anuncia minha responsabilidade pelo filho e todos os rostos que clamam por justiça. Nessa trajetória o sujeito se constitui para além da essência.
\end{abstract}

PALAVRAS-CHAVE: Subjetividade. Alteridade. Existente. Ética.

\footnotetext{
* Doutora em Psicologia Clínica pela PUC/SP e Professora do Mestrado de Psicologia da PUC/MG, Psicóloga Clínica. E-mail: jackdrawin@yahoo.com.br

** Doutor em Teologia pela Universidad Pontificia Comillas, U.P.C., Espanha e Professor de Teologia do Instituto Santo Inácio, Centro de formação filosófica e teológica da Companhia de Jesus no Brasil. E-mail: ulpiano@faculdadejesuita.edu.br
} 


\begin{abstract}
This article intends to be an introduction to the thoughts of Lévinas, starting from a discussion about the issues of subjectivity. We will try to entail the levinasian philosophy, starting with the criticism to the I as it is conceived by modern thought, and then proceeding towards the author's proposal, which reveals alterity as a condition of possibility for subjectivity. Lévinas reveals that, to exist, the existent must reassure him or herself in a viril way, and by doing that, he or she takes up a position of solitude. The encounter with death will bring something that cannot be assimilated. Death appears as an alterity; Lévinas does not think of death as "nothing", but as a mystery that comes as a limit to my solitary self, and presents the possibility of the existence of something beyond myself. Following that, Lévinas brings together love and death; experiencing love is like death; it is something that takes me over, something over which I have no control; something, however, I survive. And, coming from Eros, the subject engages in the adventures of parenthood and fertility. These experiences reveal the face of the other on the offspring that announces my responsibility over the offspring and all those faces that clamor for justice. It is in this trajectory that the subject constructs him or herself outside the essence.
\end{abstract}

KEYWORDS: Subjectivity. Alterity. Existent. Ethics.

A discussão sobre o problema da subjetividade é um dos temas mais recorrentes nos debates teóricos atuais. No campo das ciências humanas, a categoria de sujeito ocupa o centro das discussões, seja para anunciar a morte do sujeito, seja para acentuar sua des-substancialização, seja para afirmar sua posição de organizador da experiência humana.

Mas o homem nem sempre se percebeu como sujeito; essa é uma experiência moderna. Podemos dizer que a categoria de sujeito é uma ideia que nasceu e cresceu ao longo da história, perpassando por diversas vicissitudes e sendo confundida com as noções de indivíduo, pessoa e eu. Não podemos negar que o ser humano sempre teve o sentimento do seu corpo como algo individual, mas a possibilidade de reflexão sobre a 
subjetividade como algo privado e a possibilidade do gozo da liberdade individual coincidem com o pensamento moderno.

Não podemos negar os antecedentes históricos da noção de individualidade nas tribos ${ }^{1}$ e nos povos latinos $;{ }^{2}$ também não poderemos negligenciar o fato de que foi com o cristianismo que a noção de persona passou a receber a forma de pessoa humana, ser envolvido com sua interioridade. Mas será a revolução científica que anunciará a necessidade da construção de uma nova categoria filosófica, o conceito de sujeito.

A revolução copernicana propõe uma nova concepção de universo, o universo infinito, e assim coloca questões cruciais para o homem moderno. $\mathrm{O}$ universo não é mais o cosmo organizado dos gregos, agora é um espaço infinito, no qual não faz mais sentido a discussão sobre o centro, e o homem se vê perdido nesse universo infinito, tentando pensar sobre sua própria vida, seu significado e finalidade. O novo, o estranho, deve ser controlado. Mas, para controlar o mundo, o sujeito deve controlar a si mesmo, fazer da sua subjetividade, através da autodisciplina, uma plataforma firme, uma garantia de certeza.

Diante da falência de tradições e da falta de referência estável, resultante da abertura de infinitos espaços, o pensamento moderno tenta constituir um novo pólo de certeza. O que nos resta depois da destruição do cosmo finito e de Deus? O Eu responde o pensamento moderno. Não

\footnotetext{
${ }^{1}$ Ver MAUSS, Marcel. Uma categoria do Espírito humano: A noção de pessoa, a noção do eu. In: Sociologia e Antropologia. São Paulo: Edusp/EPU, 1974. Para mostrar a ausência da noção de privacidade na concepção antiga de eu, podemos citar os índios pueblos. Nessa cultura os nomes referem-se a papéis; o nome é um espelho do papel. Ele/o morador, o índio, se torna sujeito na medida em que perde a individualidade para se inscrever num todo, quando sai de uma singularidade que não tem lugar de significação para ocupar um lugar e exercer um papel que já estão lá, ordenados e significados de antemão, num universo relacional. (grifo nosso)

2 Não podemos deixar de mencionar que, segundo Vernant, a palavra indivíduo é marcada por uma a polissemia: teríamos o indivíduo propriamente dito, que se refere ao lugar institucional; o sujeito, quando o indivíduo fala em seu próprio nome; e o eu, a pessoa que traz a marca da interioridade e unicidade. Assim, embora os gregos clássicos e arcaicos tenham a experiência de um eu, da sua pessoa, da sua singularidade corporal, essa experiência é organizada de forma diferente da nossa. Ela é, psicologicamente, rasa. Não se orienta para um mundo interior. Ela é voltada para fora, para o mundo exterior.
} 
podemos ter garantias quanto a nossa percepção exterior. A visão informanos que o Sol gira em torno da Terra. O erro do conhecimento fundamentado na sensação reinou por séculos. Pode-se duvidar de tudo, mas uma certeza se pode ter: a garantia de nossa interioridade. Na busca de uma garantia de certeza, a filosofia moderna criou o Sujeito epistêmico, sede e fundamento de todas as certezas.

Assim, a subjetividade emerge e transforma-se no referencial central para o conhecimento e a verdade. Entretanto, para que o sujeito seja a plataforma firme, a sede confiável e o critério de certeza, faz-se necessário expurgar da subjetividade aquilo que a torna suspeita, não confiável. O projeto epistemológico moderno constitui o Sujeito pleno, consciente, autônomo e livre, sede e garantia de todas as verdades e certezas. Esse sujeito/substância, substrato sobre o qual está assentado o conhecimento, não se refere imediatamente ao sujeito singular, movido pelos seus sentimentos privados. Segundo Bezerra:

[...] a emergência da questão da subjetividade nos primórdios do pensamento moderno não implica o aparecimento da questão do sujeito tal como hoje é pensada. A reflexão cartesiana em torno do 'penso, logo sou' acentua a importância do verbo, e não do pronome. A singularidade do eu não está em pauta[...] (1989, p. 228)

Assim, a categoria do sujeito entra em cena no mundo filosófico, marcando a presença da metafísica da consciência; o sujeito filosófico representa o substrato último e garantia do conhecimento. Mas, paradoxalmente, essa subjetividade, sede do conhecimento, torna-se objeto através de uma exigência intrínseca do processo de produção científica. $\mathrm{O}$ sujeito reflexivo pensa o mundo e é a condição de possibilidade deste, mas, quando a operação de reflexão recai sobre seu próprio eu, este deve se ausentar. Assim, o sujeito é "des-antropologizado" e transformado em resíduo do conhecimento científico ou mero operador do método.

Drawin (1998) revela que, além do sujeito epistêmico reflexivo, o sujeito fundamento instaurado pela filosofia cartesiana, sub jectum, que não pode ser confundido com o sujeito apreendido na vivência, teremos uma nova modalidade de subjetividade racional, que é o sujeito 
epistêmico-reflexo, produzido pelo Empirismo inglês, que visa também à objetivação da subjetividade, mas partindo da experiência empírica como premissa básica. Há um paralelismo entre reflexão e sensação externa; o conhecimento do sujeito é da mesma ordem do conhecimento das coisas do mundo externo, ele é puro reflexo da exterioridade; o sujeito deve ser transformado em objeto de uma ciência especial, a psicologia científica.

E temos ainda o sujeito kantiano, o sujeito autonômico transcendental, dessubstancializado, condição de possibilidade da ciência e do agir moral. $\mathrm{O}$ ponto comum entre essas três modalidades de sujeito - o sujeito epistêmico-reflexivo cartesiano, o sujeito epistêmico-reflexo lockeano e o sujeito autonômico kantiano - é a "des-antropologização". Estas modalidades de sujeito funcionam como fundamento, como condição de possibilidade do conhecimento teórico ou prático, portanto, são concepções abstratas.

Assim, a primeira definição que podemos construir de sujeito é a que valoriza a idéia de fundamento. $\mathrm{O}$ sujeito como interioridade racional que demarca seu território próprio. A existência deste sujeito é garantida através de um movimento solipsista. Assim, impera no início da modernidade a imagem do sujeito como consciência solitária que pensa o mundo e os outros homens a partir de si mesmo. Este sujeito solitário moderno tem o poder de vida e morte, dominação e controle da natureza e dos outros entes. É interessante perceber a viragem antropocêntrica produzida pela modernidade, que, tendo recentrado epistemicamente o universo no homem, agora o vê des-antropologizado, perdendo o que verdadeiramente o caracteriza como humano: a relação com o outro.

Nesse sentido, gostaríamos de apresentar a concepção de subjetividade de Lévinas, que enfatiza precisamente o atravessamento do outro como condição de possibilidade da subjetividade. O sujeito só é sujeito na e pela relação com o outro. Lévinas entende a constituição da subjetividade como um processo que tem seu ponto de partida na fantasia moderna de um $\mathrm{Eu}$ arrogante, viril e ativo. Esta arrogância encontrará o mistério da morte, que revela o campo da alteridade, o limite para a virilidade gozosa do eu, que até então assimilava tudo, transformando o diferente em mesmo. $\mathrm{O}$ encontro com o outro, que não pode ser reduzido ao mesmo, possibilita a constituição da subjetividade. 
Mas este encontro revela a verdade que o outro é, anterior ao eu arrogante. $\mathrm{O}$ eu desconhecia essa verdade porque, segundo Lévinas, "o eu não conhece nada aquém de sua liberdade" (LÉVINAS, 1972, p. 90), sendo que a primeira experiência de liberdade se inscreve exatamente na constituição desse eu que se diferencia no nada, mas ainda é uma liberdade solitária. Assim, do ponto de vista lógico, o eu é anterior ao outro, pois só é possível demarcar as fronteiras quando as unidades estão estabelecidas, mas do ponto de vista da criação o outro é anterior ao eu e é sua condição de possibilidade. Por esse motivo o sujeito se constitui na e pela relação com o outro.

Em Lévinas (1947), a primeira ação necessária para a constituição do sujeito é a hipóstase. Mas, antes da reflexão sobre a afirmação de si, o autor inicia uma discussão com o pensamento heideggeriano sobre a problemática da existência e do existente. Para Lévinas (1947), a expressão de Heidegger "Geworfenheit" (o-fato-de-ser-jogado-em) conduz ao erro de se pensar em uma existência (Ser) anterior e independente do existente. Essa existência ( $i l$ $y$ a) seria um $\mathrm{Ser}^{3}$ anônimo, impessoal, no qual não haveria nenhum raio de luz e liberdade, nem uma inscrição do tempo humano.

Lévinas (1947) busca a experiência da insônia para metaforizar essa pura existência que é relacionada com a ideia de mal, na medida em que é pura determinação, não há saída. Segundo o autor, "a insônia é feita da consciência de que isso não acabará jamais, isto é, de que não existe nenhum meio de retirar-se da vigilância a que se é forçado" (LÉVINAS, 1947, p. 4). A insônia seria uma experiência sem liberdade e sem a possibilidade da consciência sair de si mesma, ou seja, sem evasão. Podemos pensar, paradoxalmente, que na insônia temos uma consciência sem-si; não uma consciência em-si, mas uma ausência de si.

Para Lévinas (1947), quem existe é o existente. Essa existência como ser anônimo aparece no autor como um conceito negativo, a positividade surge com a vida, com os entes. "O ser é o mal não porque seja finito, mas porque não tem limites" (LÉVINAS, 1947, p. 5). O existente rompe com a eterna vigília anônima do il y a. Este ato em que o existente passa a existir,

${ }^{3}$ Sobre o problema do Ser na obra de Lévinas, remeto o leitor à tese: KORELC, Martina. O problema do ser na obra de E. Lévinas 2006. Tese de Doutorado. Faculdade, Universidade Católica do Rio Grande do Sul, Rio Grande do Sul, 2006. 
Lévinas (1947) chama de hipóstase. Hipóstase é o evento ontológico no qual o existente contrai existência. Para existir, o ente precisa se afirmar, demarcar seus limites e se presentificar, ainda que o preço seja o tédio e a solidão.

$\mathrm{Na}$ gênese da subjetividade humana, o existente se afirma na existência. Na hipóstase ocorre o advento do sujeito, que pode ser descrito neste momento através da viril posição afirmativa, da arrogante consciência de si. Mas esse eu soberano está preso aos instantes de si mesmo. O existente constituído como senhor viril, como identidade, está necessariamente só, é monoda. A tragicidade essencial do ente que existe é estar condenado à solidão, ser prisioneiro do seu próprio corpo. A hipóstase possibilita a criação do ente, mas em um mesmo movimento une vida e solidão. Estar preso a si mesmo é nauseante.

Segundo Fabri, "a náusea está no núcleo de um conflito permanente que caracteriza a consciência" (FABRI, 1997, p. 31). A hipóstase se realiza em um presente constante. $\mathrm{O}$ ente que existe se apreende por instantes fugidios, sem extensão no tempo. No ato da existência o ente promove uma ruptura no eterno do "il y $a$ " e se faz duplamente presente. Presente como presença afirmativa e também como tempo. Assim, uma primeira dimensão temporal aparece, pois "o presente é uma situação no ser em que não há somente ser em geral, mas em que há um ser, um sujeito" (LÉVINAS, 1947 A, p. 89). Mas esse tempo presente é prisioneiro de si mesmo, não flui. Podemos dizer que é um tempo sem tempo, porque interrompe e reata consigo mesmo, não escapa do instante que é a vida, mesmo que inscrita dentro de uma duração biológica.

$\mathrm{O}$ eu é essa experiência concreta de solidão experimentada nos instantes evanescentes. Para Lévinas, esse eu ainda não é um sujeito, porque ele ainda não ek-sisti; é preciso sair de si sem retorno a si para existir. Assim como o conceito de hipóstase é fundamental na definição de subjetividade de Lévinas, também é o conceito de evasão. Fabri revela que a evasão é a "necessidade de sair de si mesmo, quer dizer, romper o encadeamento mais radical, mais irremissível, o fato de que o eu é si mesmo.” (FABRI, 1997, p. 26-27). E acrescenta: "a evasão não provoca nenhuma espécie de retorno a si mesmo" (FABRI, 1997, p. 36). Retomando a discussão sobre a hipóstase, podemos dizer que o eu hipostaseado é livre. Essa primeira liberdade aparece como auto-afirmação, como autonomia, a 
liberdade de uma diferenciação dentro do anônimo do il y a. Parece que o sujeito da consciência, de Descartes e de Kant, é prisioneiro desta primeira liberdade. Lévinas revela:

Ação, liberdade, começo, presente, representação - memória e história - articulam de diversas maneiras a modalidade ontológica que é a consciência. (1972, p. 88)

Paradoxalmente, essa primeira liberdade diante do determinismo absoluto do impessoal il y a conduz o eu hispostaseado a uma prisão solitária no seu próprio corpo. Dessa forma, a solidão que Lévinas descreve não é privação do outro, mas a solidão de não poder sair de si mesmo. $\mathrm{O}$ eu experimenta orgulho, virilidade e soberania, mas também vivencia as amarguras da solidão. $\mathrm{O}$ existente é livre dentro da existência, mas é prisioneiro de si, porque não pode se desprender de si mesmo, pois se assim fizesse não seria um eu. A solidão não é algo contingente, é necessária para a existência do ente. É necessário que haja solidão para haver liberdade de um começo. Mas, para que o sujeito realmente seja sujeito, é preciso sair de si.

Vazquez explica que esse ente é solitário porque "é incapaz de tempo e, portanto, é incapaz de romper com o laço que une o 'eu' a 'simesmo"” (VAZQUEZ, 1982, p. 113). A solidão é a falta de tempo, o ente só existe nos instantes. É preciso o tempo para desatar os laços da hipóstase. O tempo como geração, enlaçamento com o outro e, portanto, aposta, não poderia surgir do in-divíduo, este só pode oferecer o presente. O eu busca na vida cotidiana maneiras de se libertar do cativeiro da identidade. Essas tentativas de saída acontecem através do gozo. Mas o gozo se revela como um esquecimento de si, e não como uma saída de si.

Lévinas (1947) busca na fenomenologia do sofrimento e da dor respostas para a aporia do eu preso em si mesmo. O sofrimento seria uma experiência de solidão exacerbada, uma prisão a si, na qual o tempo não flui, ou seja, a vivência do tempo do sujeito em dor e sofrimento é a do eterno agora. "Há no sofrimento uma ausência de todo refúgio" (LÉVINAS, 1947, p. 12). Mas, por outro lado, o sofrimento apresenta a face da morte. Lévinas vê esse encontro repleto de luz, pois o encontro com a morte (e não o morrer) anuncia um campo em que o sujeito não pode ser viril, não 
pode assimilar gozosamente.

Dessa forma, o autor vê a morte como mistério, como possibilidade de saída de si, de libertação da sua materialidade, à qual está condenado. A morte como limite para a virilidade é pura alteridade. Parece-nos importante ressaltar que o autor não está falando do morrer, porque morrer é voltar a um estado de irresponsabilidade. Então, Lévinas pensa no encontro com a morte sem ser tomado por esta, pois ao morrer o eu perde sua identidade. A morte é algo absolutamente outro que não posso assimilar pelo gozo; assim, a morte é uma alteridade que quebra minha solidão. Nas palavras de Lévinas:

Esta aproximação da morte indica-nos que nós estamos em relação com algo que é absolutamente outro, algo que possui a alteridade, não como uma determinação provisória, algo que nós podemos assimilar pelo gozo, mas algo cuja existência mesma é feita de alteridade. (LÉVINAS, 1947, p. 14)

O encontro com a morte aponta para uma realidade diferente da minha. Assim, percebo que a existência é plural. A possibilidade de um objeto no qual o sujeito sempre pode ser dono, soberano e viril acentua a solidão. A morte introduz a abertura ao outro e a possível saída da solidão, porque o sujeito não pode ser dono da morte.

Mas o ente pode entrar em relação com a alteridade sem se deixar esmagar pelo outro? Sem perder o seu si-mesmo? O tema da morte lança luz sobre o problema da alteridade, mas o morrer cobra a liberdade oferecida através do apagamento da hipóstase. É preciso trabalhar outro encontro que retire o eu da solidão, mas não o esmague. Lévinas (1947) aproximará a morte de Eros. O autor revela:

O amor não é uma possibilidade, ele não é devido a nossa iniciativa, ele não tem razão, ele nos invade e nos fere, e, porém, o eu sobrevive nele. (LÉVINAS, 1947, p. 20)

Lévinas faz uma analogia entre o amor e a morte. As duas experiências são necessárias, e o eu não tem domínio sobre elas. $\mathrm{O}$ 
que difere o amor da morte é que o eu sobrevive no amor e na morte é esmagado. Assim, o encontro com o amor apresenta o campo da alteridade, da diferença, que não pode ser assimilado pelo eu, apresenta um limite ao eu, quebrando, pois, a solidão. O viril deve se encontrar com o feminino, deixar-se tocar por esta dimensão para se abrir ao novo, para sair de sua solidão e encontrar o outro.

Parece que a escolha da palavra "feminino" não é mero acaso. Este conceito aparece como par suplementar à noção de viril, expressão que é utilizada pelo autor para nomear a solidão do existente hipostaseado. Faz-se necessário uma ressalva: a categoria de feminino não se restringe à mulher. Lévinas pensa em uma efeminação do sujeito como saída da solidão da hipóstase. O sujeito alcança o status de sujeito quando se abre para o feminino, ou seja, o sujeito possui "sua identidade não graças a sua iniciativa de poder, mas à passividade do amor recebido" (LÉVINAS, 1961, p. 249). O amor que retira o sujeito de sua viril solidão não é o amor do Mito de Aristófanes, que procura a si mesmo, um amor incestuoso que regressa a si, que não encontra a alteridade. $\mathrm{O}$ amor que retira o aspirante a sujeito da sua solidão é o amor que anuncia a diferença, que escapa ao gozo mortífero do eu viril.

Assim, o amor anunciando por Lévinas se aproxima mais da tese platônica apresentada por Diotima através do personagem de Sócrates. Essa tese revela que o Amor deseja aquilo que não tem, e por esse fato é carente; cai por terra a ideia de que ele seja um deus. O Amor é o filósofo por excelência, pois, consciente de sua falta, sai à procura daquilo de que necessita para ser melhor. Assim, a natureza mortal tenta, na medida do possível, ser imortal, pois esse é o único meio de alcançar a durabilidade do bem.

Por causa disso, a geração aparece como um desejo ardente de um corpo ou de uma alma enamorada, já que a descendência assegura o novo para substituir o passado, e é assim que se garante a permanência das espécies. Apesar de num primeiro momento sermos levados a pensar em descendência de filhos, o diálogo entre Diotima e Sócrates deixa claro que mais importante que a geração nos belos corpos é a geração em belas almas. O Amor nos possibilita a experiência de uma vida imortal e divina. Nesse sentido, o amor é filho da penúria e da abundância, pois o que o move é a carência, mas o que alcança é a elevação. 
Segundo Lévinas (1961), o amor visa o outro na sua fraqueza. "Amar é temer por outrem, levar ajuda à sua fraqueza" (LÉVINAS, 1961, p. 235). A volúpia que possibilita a transcendência alimenta-se da simultânea dualidade da fusão e distinção. A carícia constitui uma experiência paradigmática para descrever esse encontro com o outro, no qual o eu não pode devorar o outro e regressar a si. "Na carícia o que lá está é procurado como se lá não estivesse" (NUNES, 1993, p. 182). O sujeito toca o outro sem se apoderar dele e no momento em que toca o outro, toca a fragilidade de ambos. Assim, a carícia vai além do ente. Lévinas revela:

O carnal, o terno por excelência e correlativo da carícia, a amada, não se confundem nem com o corpo-coisa do fisiologista, nem com o corpo próprio do "eu posso, nem com o corpo expressão, assistência à sua manifestação [...]Na carícia, relação ainda, por um lado, sensível, o corpo desnuda-se já da sua própria forma, para se oferecer como nudez erótica. No carnal da ternura, o corpo abandona o estatuto do ente. (LÉVINAS, 1961, p. 237)

Partindo da fenomenologia da volúpia e de Eros, o autor visa alcançar uma significação ontológica que será concretizada na ideia da fecundidade. Lévinas (1972) critica Freud por abordar a sexualidade em um plano puramente humano e assim, rebaixá-la a uma procura de prazer. A volúpia é uma experiência pura que revela a face do feminino, possibilitando, pois, a saída da solidão aprisionante no eu. Segundo Lévinas:

A posse de si torna-se o estorvo por si. O sujeito impõe-se a si próprio, arrasta-se a si próprio como posse. [...] O Eros liberta desse estorvo, suspende o retorno de mim a si. (LÉVINAS, 1961, p. 250)

Parece-nos pertinente ressaltar que o encontro erótico que abre para o sujeito uma perspectiva para além de sua virilidade não é necessariamente um encontro intersubjetivo. Ou seja, o mais fundamental não é o encontro entre dois sujeitos, mas sim o encontro com a fragilidade. Lévinas vai além da ideia de intersubjetividade, porque o encontro não é simétrico. Não é exatamente o encontro entre dois sujeitos que realiza nossa humanidade. 
O homem é homem no e pelo encontro com a falta, com o limite para a subjetividade hipostaseada. $\mathrm{O}$ encontro intersubjetivo é o encontro entre duas solidões que podem permanecer em combate eterno. $\mathrm{O}$ sujeito, para se realizar, tem que abandonar sua posição viril sem ser esmagado. $\mathrm{O}$ eu deve desaparecer para sair da solidão, mas desaparecer não é o mesmo que não existir. Assim, o eu só realiza sua dimensão de sujeito quando se abre e hospeda o outro.

Por outro lado, Eros pode oferecer uma armadilha, a saber, a prisão a dois. $\mathrm{O}$ encontro amoroso, o encontro com o feminino, abre para a fragilidade, mas ainda não oferece a experiência da transcendência; oferece apenas um sinal, uma luz, um instante de abertura para a alteridade. $\mathrm{O}$ amor deve procurar o que não tem a estrutura do ente, procurar o infinitamente futuro, o que está para ser gerado. É exatamente no fracasso da comunicação do amor, precisamente naquele ponto que escapa à razão, que algo acontece para além da solidão dos seres amantes. O encontro erótico transcende a prisão do instante presente e encontra o futuro no filho gerado. A profanação da volúpia viola o segredo e desnuda o ente, revelando o mais além do rosto, que não é um mergulho no mais íntimo do eu, mas sim o encontro com o filho.

Assim, para Lévinas, "a fecundidade deve erigir em categoria ontológica, pois, numa situação como a paternidade, o retorno do eu ao si, que articula o conceito monista de sujeito idêntico, acha-se totalmente modificado" (LÉVINAS, 1961, p. 256). A paternidade e a fecundidade constituem situações concretas em que o eu transcende sem se perder ou sem voltar a si. "A paternidade é uma relação com um estranho que, sendo outro, é eu, uma relação do eu consigo mesmo que sem dúvida também não é eu" (LEVINAS, 1947, p. 115). A paternidade oferece uma transcendência, uma inscrição de tempo para a in-temporal solidão do sujeito. Graças ao filho, ao fenômeno da fecundidade ou paternidade, o sujeito pode vir-a-ser sujeito, ou melhor, o in-divíduo, a unidade da hipóstase, pode alcançar a abertura necessária para ser sujeito.

A paternidade é, pois, para Lévinas, o acontecimento concreto em que se realiza a ex-cendência, ou seja, a saída de si sem retorno a si. Mas o filho representa somente uma moratória para a solidão da hipóstase ou apresenta uma esperança, uma promessa do Bem? Para o autor, a condição 
de possibilidade de remissão da solidão atemporal do sujeito é a condição de sexuado do indivíduo humano, mas essa experiência erótica deve se abrir para a perspectiva ética, e assim teremos o encontro com o Bem.

Retomando a discussão sobre a subjetividade, podemos afirmar que esta, verdadeiramente, se realiza através de uma substituição. A subjetividade, em Lévinas, é um acontecimento e não uma essência. A subjetividade só pode se realizar no afastamento de sua essência. A transcendência implica a própria identidade do sujeito, porque implica a morte de sua substância, ou uma transubstanciação, pois sou eu no filho sendo absolutamente outro. Segundo Lévinas, "ser seu filho significa ser eu no seu filho, estar substancialmente nele, sem, no entanto, nele se manter identicamente" (LÉVINAS, 1961 p. 258). A relação com o filho põe o tempo do absolutamente futuro, o tempo do infinito, que está em um incessante recomeço.

Assim, o futuro é introduzido a partir do encontro com o outro/ filho. O tempo é constituído por minha relação com outro; portanto, exterior ao meu instante. Podemos pensar que a existência impessoal, o ily $a$, é atemporal, fora do tempo, e a hipóstase é intemporal, ou seja, apresenta uma dimensão de tempo, mas não oferece laço futuro ou passado, apenas o gozo e a dor do "flash" instantâneo do presente; não há sentido ou salvação. O tempo, como esperança, renovação, só é possível no encontro com o outro que não capturo e não reduzo a mim. É o tempo da substituição do eu no filho. O escritor Paul Auster, no livro $O$ inventor da solidão (1982), traduziu em linguagem literária a relação do pai e do filho com o tempo:

Quando o pai morre, ele escreve, o filho torna-se seu próprio pai e seu próprio filho. Ele olha para o filho e enxerga a si mesmo. Imagina o que o menino vê quando olha para ele e descobre que está se transformando no próprio pai. Inexplicavelmente, comove-se com isso. Não é apenas a visão do menino que o comove, nem mesmo a ideia de estar dentro do pai, mas sim o que ele enxerga no menino de seu próprio passado desaparecido. É uma saudade da própria vida o que ele sente, talvez uma memória de sua própria infância como filho de seu pai. Inexplicavelmente, descobre-se a tremer naquele momento, tanto de felicidade quando de dor, se isso é possível, como se estivesse indo ao 
mesmo tempo para frente e para trás, para o futuro e para o passado. E às vezes, frequentes vezes, esses sentimentos são tão fortes que sua vida não mais parece transcorrer no presente. (AUSTER, 1982, p. 81-82)

O sujeito que se realiza no acontecimento vive uma abertura que impossibilita o engodo do eu fechado em sua virilidade. Mas a característica definidora deste acontecimento é ser sempre processo. A estrutura da subjetividade, em Lévinas, se constitui a partir de uma fenda que se abre continuamente para um outro. Lévinas demarca que esta ruptura na identidade não se assemelha à ideia de Goethe do personagem Mefistófeles, ou do Inconsciente freudiano, pois, apesar de estas teorias marcarem "uma presença por detrás do eu, de um princípio estranho que não se opõe necessariamente ao eu, mas esse pode ganhar o aspecto de inimigo" (LÉVINAS, 1961, p. 251).

Em Lévinas (1961), a paternidade e a fecundidade são categorias ontológicas $^{4}$ que possibilitam um encontro para além do ente, quebrando, pois, a arrogância da identidade solitária. Mas esse acontecimento é marcado por um incessante e infinito recomeço. $\mathrm{O}$ eu hipostaseado deve sempre revisitar a abertura, ser sempre atravessado pelo outro. O filho aparece como chave que revela a verdade ética e metafísica da ex-cendência. "Mas o eu liberto da sua própria identidade na sua fecundidade não pode manter sua separação em relação ao futuro se se prender ao seu futuro no filho único". O movimento iniciado na relação erótica deve desaguar na vida social. O filho é o outro, não permite a volta ao mesmo. Sendo outro, não assimilável pelo eu, o filho revela um rosto próprio que aponta na direção de diferentes outros rostos.

Podemos afirmar que o conceito de rosto aparece em Lévinas como

\footnotetext{
${ }^{4}$ Lévinas é um crítico da ontologia, mas em diferentes passagens ele defende um status ontológico para a fecundidade e a paternidade. A intenção, neste caso, é retirar esses conceitos da sombra biológica para alcançar um espaço na discussão da transcendência. ${ }^{5}$ É para destacar a originalidade do movimento que leva da experiência erótica para a perspectiva ética que Levinas utiliza o neologismo "ez-cendência". O termo opõe-se à palavra transcendência que para o Autor não expressa suficientemente a "saída de si sem retorno a si. (VAZQUEZ, 1982, p. 110).
} 
nova categoria filosófica. Nunes (1993) oferece-nos uma exposição sobre os antecedentes deste conceito em Hegel, Rosenzweig, Picard, Dostoievski e na Bíblia. Segundo Nunes (1993), em Hegel podemos encontrar uma pequena referência sobre "o olho como expressão da alma, e em Rosenzweig o rosto assume o significado de reflexo do rosto divino" (NUNES, 1993, p. 33-34). Assim, Lévinas encontrará em Rosenzweig as bases para sua discussão ética a partir da categoria do rosto. De um lado, podemos pensar que a discussão ética surge, ainda ignorante de si mesma, como um movimento que se inicia na hipóstase solitária, mas que só se reconhece nas experiências da fecundidade e paternidade. Sendo que essas experiências revelam a verdadeira condição de ser sujeito, a saber, a substituição do eu pelo outro, através do filho, mensagem transmitida pelo rosto do filho.De outro lado, parece pertinente defender a ideia de que a reflexão ética constitui o ponto de partida e de inspiração da filosofia levinasiana.

Dessa forma, a categoria do rosto se impõe como verdade a ser desvelada por princípio. Mas não importa o ponto de partida. Interessa-nos compreender por que elevar o rosto à condição de categoria filosófica. A filosofia de Lévinas se aproxima do método kierkegaardiano de filosofar, ou seja, deve-se privilegiar a experiência da pessoa concreta. Assim, a ética em Lévinas é mais que uma relação, é uma experiência. E, na minha experiência relacional com os outros entes, o rosto dos mesmos se destaca, revelando a luz de suas almas e a epifania do divino. O rosto é o modo em que o outro se apresenta a mim, pois o Bem se manifesta através do rosto. $\mathrm{O}$ encontro face-a-face, o rosto que me vê e o rosto que eu vejo revelam que o sujeito se encontra para além da essência, exatamente na passagem para o outro que ser.

Faz-se necessário ressaltar que não se trata de um outro modo ser, mas sim de um outro no ser e um ser no outro, ou seja, um movimento que retira o eu de sua solidão e une os sujeitos no tempo e na história humana. É um "ser" que, no movimento de existir, se perde e se acha no outro. Os limites da linguagem ocidental não permitem representar essa experiência de subjetividade que se situa para além da essência, que não se pretende cristalizada e fixada em um modo arrogante de ser. O rosto do outro se destrói em cada instante e ultrapassa a imagem plástica que ele me deixa, porque o rosto "diz", revela a afetação do Bem. Se pretendermos reduzir o outro 
ao mesmo, perderemos o nosso encontro em tematizações que produzem categorias estáticas, alcançando apenas o dito, não saído do nosso eu.

É preciso ver o rosto, arriscar para além da essência, permitir o vislumbre do dizer. Tentar enunciar o "outro que o ser" é trair o seu mistério e prendê-lo no dito. Gorz (2007), em sua carta de despedida e de exaltação do amor por sua esposa Dorine, expressa a diferença entre o dizer e o dito: "[...] quando tudo tiver sido dito, tudo ainda ficará por dizer, sempre restará tudo a dizer - em outras palavras, é o dizer que importa, não o dito [...]"(GORZ, 2007/2008, p. 46). Precisamos do dito, mas não podemos esquecer que o Bem escapadas prisões conceituais. No encontro amoroso e no ético algo se dá para além do dito, sendo que é o rosto que aponta para o "diferentemente de ser" situado nessas duas experiências humanas. Assim, o rosto do filho clama por minha responsabilidade, demanda ação e posição ética, e não um excesso de teorização. Parece interessante ressaltar que, após a experiência da paternidade, os sujeitos se sentem um pouco "pais" das outras crianças. Um campo de sensibilidade é aberto, e os rostos de todas as crianças emanam uma luz similar à luz do rosto de seu filho. E os pais não tem nome próprio para o filho, a criança grita mãe ou pai e não um nome específico. Pois, não importa a sua identidade, seu nome próprio; importa o amor que você deve doar ao outro que clama por mãe ou pai.

Dessa forma, não sendo o filho único, a subjetividade se converte em responsabilidade pelo outro. O rosto do filho pode ser compreendido como chave que desvela outros rostos. No momento em que vejo o rosto do filho e compreendo minha responsabilidade por ele, meus olhos se abrem para ver os diferentes rostos que circulam na minha história. Será por meio do discurso, da linguagem como patrimônio de um povo e do tempo do futuro, introduzido pelo outro/filho, que a responsabilidade se apresenta à subjetividade. Podemos dizer que, no pensamento levinasiano, vale o mandamento: ama teu próximo, porque só assim serás um homem.

A subjetividade em Lévinas (1961) não se reduz a um eu viril nem faz sua entrada no campo da alteridade através de uma totalização integradora e mortífera em relação ao outro. A fecundidade e a paternidade abrem caminho para o outro, mas um caminho processual e descontínuo; um caminho que atesta o caráter do encontro com o ser, ou melhor, com o outro que o ser. $\mathrm{O}$ encontro com o outro, com o rosto iniciado com Eros, formalizado com a 
paternidade e a fecundidade, realiza a evasão em direção ao infinito, ao Bem, e, assim, a superação do mal no ser e o encontro com a ética.

Assim, a filosofia de Lévinas, denominada filosofia da diferença, irá representar um grande campo crítico à concepção do sujeito como identidade. O autor, em sua crítica cerrada ao pensamento de Husserl, anunciará a arrogância imaginária da consciência que acredita na equação "eu igual a eu". A filosofia da diferença concebe o sujeito como um processo contínuo e atravessado pela lógica alteritária. Do ponto de vista lógico, o eu é anterior ao outro, mas do ponto de vista "criacional" o outro é anterior ao eu. Assim, a partir da lógica da alteridade, podemos criticar a noção de sujeito/substância que crê na sua identidade, na autonomia total e na estabilidade "mortífera". A subjetivação é um processo contínuo aberto às afetações alteritárias (internas/ externas), e o mais importante, não existe um ponto de "acabamento final". Os processos de subjetivação revelam a condição humana pendular que oscila entre o campo do eu e o do outro; a permanência no campo do eu parece um sonho moderno.

\section{Referências}

AUSTER, Paul. O inventor da solidão. São Paulo: Círculo do Livro, 1982. BEZERRA, Benilto. Subjetividade moderna e o campo da psicanálise. In. BIRMAN, J. Freud 50 anos depois. Rio de Janeiro: Relume Dumará, 1989, p. 219-240.

COSTA, Luis Márcio. Lévinas: uma introdução. Petrópolis, R.J.: Vozes, 2000.

DRAWIN, Carlos. Roberto. As seduções de Odisseu: paradigmas da subjetividade no pensamento moderno. In: Cultura da Ilusão. Rio de Janeiro: Contra capa, 1998, p. 9-36.

FABRI, Marcelo. Desencantando a ontologia: subjetividade e sentido ético em Lévinas. Porto Alegre: EDIPUCRS, 1997.

GORZ, André. Carta a D. - História de um amor. São Paulo: Annablume, 2008.

KORELC, Martina. O problema do ser na obra de E. Lévinas. 2006. $371 \mathrm{f}$. 
Tese (Doutorado em Filosofia) - Pontifícia Universidade Católica do Rio Grande do Sul, Rio Grande do Sul, 2006.

KUIAVA, E. A. Crítica de Levinas à Estrutura da Subjetividade Kantiana. Veritas (Porto Alegre), Porto Alegre - RS Brasil, v. 44, n. 2, p. 297-310, 1999.

LÉVINAS, Emmanuel (1947). Le temps et l'Autre. Paris, Fata Morgana, 1979. Tradução Livre: Ulpiano Vázquez e Edgar Piva.

LÉVINAS, Emmanuel (1947A). Da existência ao existente. Campinas: Papirus, 1999.

LÉVINAS, Emmanuel. (1972). Humanismo do outro Homem. Petrópolis: Vozes, 1993.

LÉVINAS, Emmanuel (1961). Totalidade e Infinito. Lisboa: Edições 70, 1988.

LOBO-HADDOCK, R. Da existência ao infinito-Ensaios sobre Emmanuel Lévinas. São Paulo/Rio de Janeiro: Loyola e Ed. PUC/Rio, 2006.

NUNES, Etelvina. P. L. O outro e o rosto - Problema da Alteridade em Emmanuel Lévinas. Braga: Faculdade de Filosofia da UCP, 1993.

PEÓN, J. A. Sucasas. La subjetivación. Hipóstasis y gozo. Revista Antropos, $\mathrm{n}^{\circ}$. 176. Barcelona, enero-febrero, 1998.

PLATÃo. Diálogos: O Banquete; Fédon; Sofista; Político. São Paulo: Abril Cultural, 1972. 269 p.

RIBEIRO JÚNIRO, N. Sabedoria de amar - a ética no itinerário de Emmanuel Lévinas. São Paulo: Loyola, 2005.

SOUZA, R. T. Sujeito, ética e história: Lévinas, o traumatismo infinito e a crítica da filosofia ocidental. Porto Alegre: EDIPUCRS, 1999.

VAZQUEZ, Ulpiano Moro. El discurso sobre Dios em la obra de E. Lévinas. Madri: Madri, 1982.

Data de registro: $24 / 09 / 08$ Data de aceite: $28 / 08 / 09$ 